\title{
Molecular Diagnostic Approach Prevails Superior Over Conventional Gel- Electrophoresis Method in Detecting Sickle Cell Anemia
}

Khadiza Begum¹, Mohammad Abdul Mannan ${ }^{2}$, Mousumi Sanyal ${ }^{2}$, Md. Ismail Hosen ${ }^{3}$, Sajib Chakraborty ${ }^{3 *}$ and Hossain Uddin Shekhar ${ }^{3 *}$

${ }^{1}$ Department of Medicine, Ad-Din Medical College Hospital, Dhaka, Bangladesh

${ }^{2}$ Dr. Sirajul Islam Medical College Hospital, Dhaka, Bangladesh

${ }^{3}$ Department of Biochemistry and Molecular Biology, Dhaka University, Dhaka, Bangladesh

\begin{abstract}
Sickle cell anemia is defined as homozygosity caused by the mutation of the glutamic acid residue to valine in the $\beta$-globin gene. Sickle cell disease is an increasing global health burden with the estimated number of patients increasing in a concerning manner. Here we report a very interesting and clinically insightful case of hemoglobinopathy which was initially suspected to be $\mathrm{Hb}$ S/D Punjab- a rare type of hemoglobinopathy as diagnosed by the hemoglobinelectrophoresis technique. Despite the diagnosis report indicating the rare $\mathrm{Hb} S / \mathrm{D}$ Punjab, the uncharacteristic clinical presentation of the patient which was not coherent with the classical symptoms of $\mathrm{Hb}$ S/D Punjab, forced the clinicians to turn their attention to molecular diagnosis. To clarify the etiology of the clinical case, a sequencing-based molecular diagnosis approach was adopted that revealed the mutational signature of sickle cell anemia (SCA). This case can be regarded as a prominent example where the molecular techniques lead to the correct diagnosis matching with the clinical symptoms while the conventional diagnostic approach failed.
\end{abstract}

Keywords: Sickle Cell Anemia (SCA); Haemoglobinopathies; Hemoglobin SO Arab disease

\section{Introduction}

Sickle cell anemia (SCA) is one of the most common inherited qualitative haemoglobinopathies. Around $10 \%$ of Sickle Disease patients die by the age of 1 year and in many sub-Saharan countries mortality is even higher. It is also not uncommon in some parts of India and among people of African origin living in other parts of the world [1].

SCA is an autosomal recessive disease where the predominant haemoglobin is HbS which is usually absent in healthy adult. The term "Sickle Cell Disease" includes Sickle cell Anaemia (HbSS) hemoglobin SC disease (HbSC) and hemoglobin beta thalassemia. There are also a few rare types of sickle cell disease: hemoglobin SD disease (HbSD), hemoglobin SE disease (HbSE), and hemoglobin SO Arab disease.

Sickle cell anaemia, is basically, a homozygosity caused by the mutation of the glutamic acid residue to valine in the $\beta$-globin gene [2]. $\mathrm{HbS}$ molecule undergoes changes in the event of deoxygenetion. The change distorts the RBC in such a manner that it assumes an elongated crecentric/sickle shaped. Sickling of RBC is initially reversible. However red cell membrane damage occurs with each episodes of sickling and eventually the cell accumulates calcium and lose $\mathrm{K}+$ and water and becomes irreversibly sickled [3].

In HbSS, the complete blood count reveals very low haemoglobin; sometimes in the range of 6-8 g/dl with a high reticulocyte count. Sickling of the red blood cells, on a blood film, can be induced by the addition of sodium metabisulfite. Abnormal haemoglobin forms can be detected on haemoglobin electrophoresis. Genetic testing is rarely performed [4].

\section{Case Summary}

A 65-year-old gentleman was presented with progressively increasing generalized body ache and confusion for last 2 weeks. He worked as a painter and was never hospitalized before. His past medical history was non-significant; except gradual onset of generalized weakness for last 3 years which was more prominent on exertion. $\mathrm{He}$ was diagnosed as microcytic hypochromic anaemia 3 months back and was treated with injectable iron without any significant outcome. On examination, he was restless and confused, moderately anaemic, no focal neurological sign or organomegally was found. He has no history of travelling to Malaria endemic zone. However, collateral history from his family revealed that his elder son is a diagnosed patient of Thalassemia major since childhood and needs blood transfusion on regular basis. Other family members are of normal health.

On admission, his blood reports showed severe microcytic hypochromic anaemia with high ESR and neuthrophilic leucocytosis and abnormal platelet count (Table 1). Peripheral blood film showed leucoerythroblastic blood picture with thrombocytopenia. His urine showed pus cells, but blood and urine culture did not show any growth. As a supporting evidence of sepsis, D-Dimer was high. The patient was transferred to the High dependency care unit for further management. We started injectable antibiotics. His LDH came very high so we repeated the PBF and it showed features of heamolysis. To correct the anaemia and thrombocytopenia, we transfused three units of whole blood. His hemoglobin $(\mathrm{Hb})$ level improved; however, there was no improvement in his clinical condition. Moreover, serum sodium started rising up.

*Corresponding author: Sajib Chakraborty, Department of Biochemistry and Molecular Biology, University of Dhaka, Bangladesh, Tel: 880-2-9661920-73 (7643); E-mail: sajib@du.ac.bd

Hossain Uddin Shekhar, Department of Biochemistry and Molecular Biology University of Dhaka, Dhaka, Bangladesh, Tel: 880-2-9661920-73 (7643); E-mail hossainshekhar@du.ac.bd

Received February 18, 2018; Accepted February 26, 2018; Published February 28, 2018

Citation: Begum K, Mannan MA, Sanyal M, Hosen MI, Chakraborty S, et al (2018) Molecular Diagnostic Approach Prevails Superior Over Conventional GelElectrophoresis Method in Detecting Sickle Cell Anemia. J Mol Biomark Diagn 9: 382. doi: 10.4172/2155-9929.1000382

Copyright: $\odot 2018$ Begum K, et al. This is an open-access article distributed under the terms of the Creative Commons Attribution License, which permits unrestricted use, distribution, and reproduction in any medium, provided the original author and source are credited. 
Going retrospectively, we looked at his previous reports which revealed that he had been seeking opinion for last few months and all the time blood tests showed moderate to severe microcytic hypochromic anemia with high ESR. Among several PBF reports, one showed few sickle cell, for which he was advised for $\mathrm{Hb}$ electrophoresis. Interestingly, $\mathrm{Hb}$ electrophoresis showed $\mathrm{Hb} \mathrm{SD}$ Punjab (Figure 1). As it is a rare type of disease, we went for gene study to confirm the disease. We kept the differential of Hemolytic uraemic syndrome in mind as the renal function was impaired. In the mean time we were treating him for hypernatremia and anemia as well as sepsis. We ensured his oxygen, hydration, nutrition and sepsis control. The hyponatremia was corrected but still he was confused. So, we transferred him to another hospital where plasmapheresis facilities are available. However, the follow up with the family updated that, he responded well with the supportive care only and within five days, was discharged. Later, we got the Gene study report and it confirmed Sickle Cell Anemia.

\begin{tabular}{|c|c|c|}
\hline Parameter & Result & Comments \\
\hline Hemoglobin $(\mathrm{Hb})$ & $6.3 \mathrm{~g} / \mathrm{dL}$ & Low \\
\hline ESR & $50 \mathrm{~mm} / 1^{\text {st }}$ hours & Severely high \\
\hline RBC count & $2.23 \times 10^{12} / \mathrm{L}$ & Moderately low \\
\hline WBC count & $12 \times 10^{9} / \mathrm{L}$ & Normal \\
\hline Platelet count & $855 \times 10^{9} / \mathrm{L}$ & High \\
\hline Serum LDH & $3872 \mathrm{U} / \mathrm{L}$ & Severely high \\
\hline
\end{tabular}

Table 1: Complete blood count of the patient.

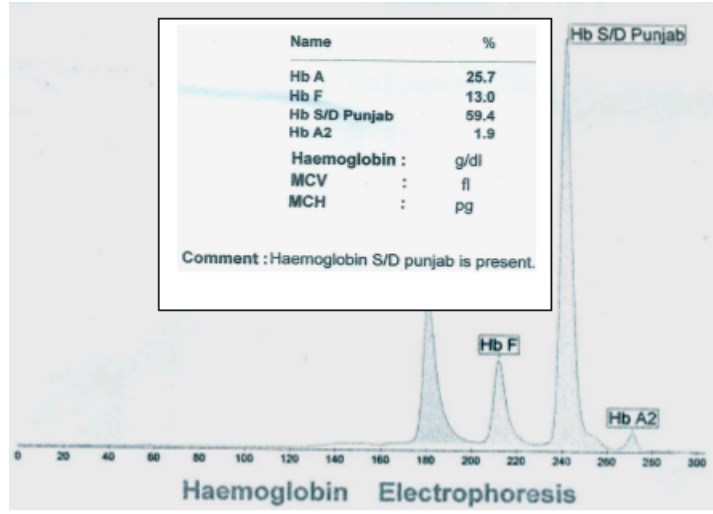

Figure 1: Hemoglobin electrophoresis report of the patient showing $\mathrm{Hb} \mathrm{S} / \mathrm{D}$ Punjab value to be high.
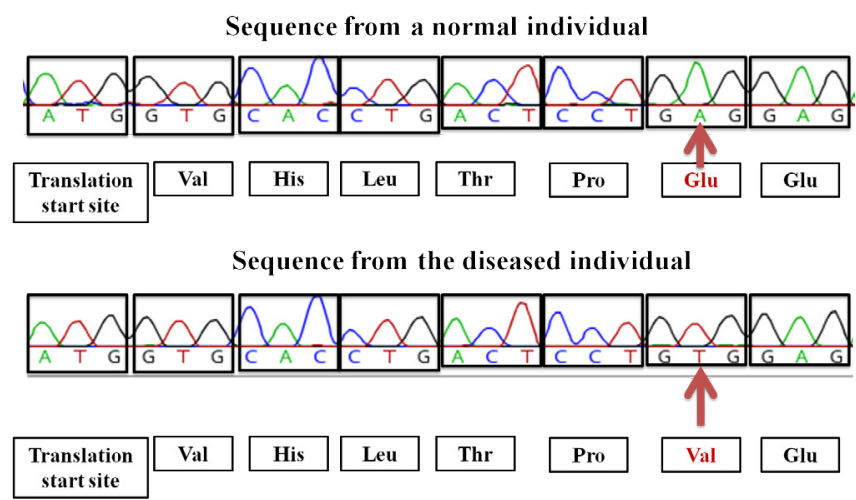

Figure 2: Sequencing of the beta globin gene shows that the proband (the affected individual) in this case carries a homozygous $A>T$ mutation at the codon 6 ; thus, changing the amino acid from glutamic acid to valine. The upper panel shows the sequence from a healthy individual and the lower panel is from the affected individual.

\section{Molecular Analysis: Identification of Sickle Cell Anemia by Sanger Sequencing}

Genomic DNA was extracted from the whole blood of the patients using the Qiagen genomic DNA extraction kit (Qiagen, Germany). Molecular analysis was performed by sequencing of the entire coding region (Exon I, II and II), part of intron I and 2, promoter region and splice junction site of the beta globing gene. The genomic DNA extracted from the peripheral blood and the amniotic fluid was amplified using the polymerase chain reaction (PCR) method. Sequencing reaction was carried out by BigDye terminator cycle sequencing kit (Applied Biosystems, USA). Analysis was performed by automated capillary electrophoresis in the 3500-genetic analyzer (Applied Biosystems, USA).

The sequences obtained from the capillary electrophoresis were then aligned using the reference sequence of the beta-globin gene in the Seqscape sequence alignment software version 2.5 (Applied Biosystems, USA). The observed genetic variants were then analyzed for their clinical significance in the HbVar database of hemoglobin variants and thalassemia mutations [3]. We found a homozygous mutation at the codon 6; altering the amino acid from Glutamic acid to Valine (Figure 2).

\section{Discussion}

Several cases have been reported on teen aged population with denovo diagnosis of SCD with complications. After clinical suspicion, diagnosis was confirmed by $\mathrm{PBF}$ and $\mathrm{Hb}$ electrophoresis. In this case, this 65-year-old gentleman had been symptom free till his $5^{\text {th }}$ decade. He had never experienced any complication apart from last 3 years while he faced progressive generalized weakness which can be explained by onset of anaemia. For last few weeks he had been complaining of severe bone pain. The onset of sepsis might be the cause of vasoocclusive crisis which results in severe generalized bodyache. And sepsis itself can be a cause of renal failure moreover in SCD, kidneys lose the concentrating capacity which can progress to hypernatraemia. The sepsis might be the main trigger to cause the confusion as well.

In sickling crisis, there may be haemolysis as well which is also evident here by high LDH, progressive anaemia instead of previous blood transfusion and haemolytic blood picture. In first instance it was confusing to get $\mathrm{Hb} \mathrm{S} / \mathrm{D}$ Punjab in $\mathrm{Hb}$ electrophoresis as we expect clear cut $\mathrm{Hb}$ electrophoresis result in SCA. Basically, $\mathrm{Hb}$ SD is a variety of SCD as in heterozygote form which may cause mild to moderate disease. But it is not suitable at all with this patient with acute crisis. So, we did the gene study and it confirmed the homozygous SCA which explains the progressive anaemia, haemolysis, hypernatraemia caused by dehydration and isosthenuria. However, it is rare to present with anaemia in this age as well as all these complications.

\section{Conclusion}

The aim of reporting this case is to aware the medics and biologists about the atypical presentation of Sickle Cell Anaemia as well as the diagnostic accuracy with molecular diagnostic approach in such diagnostic dilemma.

\section{References}

1. Elzouki AY, Harfi HA, Nazer H, Oh W, Stapleton FB, et al. (2012) Textbook of clinical pediatrics (2nd edn), Springer, Berlin, Germany.

2. Piel FB, Steinberg MH, Rees DC (2017) Sickle Cell Disease. NEJM 376: 1561-1573.

3. Singh S, Khawale SD (2013) Sickle cell anemia: A case study. Ann Ayur Med 2: 29-32.

4. Clarke GM, Higgins TN (2000) Laboratory investigation of haemoglobinopathies and thalassemias: review and update. Clin Chem 46: 1284-1290. 